\title{
Erratum to: Delayed Gastric Emptying After Pancreaticoduodenectomy: Is Subtotal Stomach Preserving Better or Pylorus Preserving?
}

\author{
Mena M. Hanna ${ }^{1} \cdot$ Rahul Gadde $^{1,2}$ - Leonardo Tamariz ${ }^{2}$ - Casey J. Allen ${ }^{1}$. \\ Jonathan P. Meizoso ${ }^{1}$ • Danny Sleeman ${ }^{1,3}$ - Alan S. Livingstone ${ }^{1,3}$ - Danny Yakoub ${ }^{1,3,4}$
}

Published online: 1 July 2015

(C) 2015 The Society for Surgery of the Alimentary Tract

Erratum to: J Gastrointest Surg

DOI 10.1007/s11605-015-2816-1

Several of the authors of this paper didn't include their middle initials in the author list. The above list reflects that correction.

The online version of the original article can be found under http://dx.doi. org/10.1007/s11605-015-2816-1.

Danny Yakoub

dyakoub@med.miami.edu

1 Division of Surgical Oncology, Department of Surgery, University of Miami Miller School of Medicine, Miami, FL, USA

2 Department of Internal Medicine, University of Miami Miller School of Medicine, Miami, FL, USA

3 Sylvester Comprehensive Cancer Center, University of Miami Miller School of Medicine, Miami, FL, USA

4 Division of Surgical Oncology, University of Miami Miller School of Medicine, Jackson Memorial Hospital/Sylvester Comprehensive Cancer Center, 1120 NW14th Street, CRB C232, Miami, FL 33136, USA 